\title{
The Normative Analysis of China's Land Reclamation Annual Report Review Clauses
}

\author{
By Dong Yahui \& Zhao Oian
}

Southwest University Abstract- Perfecting the review of the annual report of land reclamation is extremely important to reform the annual report system of land reclamation, which is helpful to the effectiveness of land reclamation supervision. The review of the annual report of land reclamation means that the subjects of land reclamation supervision review the materials or data submitted by the supervised units to realize the supervision of land reclamation activities. This article uses the research method of normative analysis to examine the relevant norms of the review of land reclamation annual report by analyzing the completeness and rationality of the review subjects and review methods of land reclamation annual report, and tries to propose to coordinate the supervision of supervisory departments and improve the working quality of supervisors in order to improve the supervisory capability of the subjects of the annual report of land reclamation, and tries to refine the off-site supervision and strengthen the coordination of off-site supervision and on-site inspection to improve the review methods of the annual report of land reclamation systematically, which will provide specific guidance for the existing review clauses.

Keywords: annual report of land reclamation; review clause; normative analysis.

GJHSS-F Classification: FOR Code: 160699p

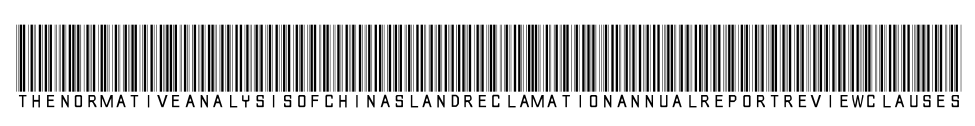

Stricty as per the compliance and regulations of:

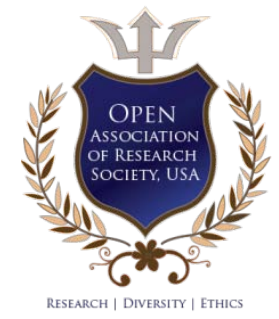

(C) 2020. Dong Yahui \& Zhao Qian. This is a research/review paper, distributed under the terms of the Creative Commons Attribution-Noncommercial 3.0 Unported License http://creativecommons.org/licenses/by-nc/3.0/), permitting all non-commercial use, distribution, and reproduction in any medium, provided the original work is properly cited. 


\title{
The Normative Analysis of China's Land Reclamation Annual Report Review Clauses
}

\author{
Dong Yahui ${ }^{\alpha} \&$ Zhao Qian ${ }^{\sigma}$
}

\begin{abstract}
Perfecting the review of the annual report of land reclamation is extremely important to reform the annual report system of land reclamation, which is helpful to the effectiveness of land reclamation supervision. The review of the annual report of land reclamation means that the subjects of land reclamation supervision review the materials or data submitted by the supervised units to realize the supervision of land reclamation activities. This article uses the research method of normative analysis to examine the relevant norms of the review of land reclamation annual report by analyzing the completeness and rationality of the review subjects and review methods of land reclamation annual report, and tries to propose to coordinate the supervision of supervisory departments and improve the working quality of supervisors in order to improve the supervisory capability of the subjects of the annual report of land reclamation, and tries to refine the off-site supervision and strengthen the coordination of off-site supervision and on-site inspection to improve the review methods of the annual report of land reclamation systematically, which will provide specific guidance for the existing review clauses.
\end{abstract}

Keywords: annual report of land reclamation; review clause; normative analysis.

\section{INTRODUCTION}

T he annual land reclamation report is an annual report that comprehensively reflects the situation of land reclamation. That is to say, the obligors of land reclamation shall report the implementations of land reclamation in the current year to the land reclamation supervision departments before December 31 of each year. The review clauses are the general terms of relevant legal norms that clarify the review items of the annual report of land reclamation. With the revision of the Regulation on Land Reclamation in 2011, the annual report system of land reclamation was established. But the review of land reclamation annual report as a vital part of the land reclamation annual report supervision, its role in practice is severely limited. It is mainly because everyone has an insufficient understanding of the annual report of land reclamation and relies on previous supervision for a long time.

Author $\alpha$ : Master degree candidate, mainly engaged in the science of land law. College of Law, Southwest University, China.

e-mail: 2995693370@qq.com

Author o: Professor, mainly engaged in the science of land law. College of Law, Southwest University, China. e-mail: swuzhaoqian@126.com

* Funding Project: The Major Project for the National Social Science fund of China under Grant 18ZDA151 "Research on Perfecting the Legal System of Land Management with Chinese Characteristics in the New Era"
Moreover, the review of the annual report of land reclamation is not perfect in the system. And it lacks relatively standardized and specific operational guidelines. To give full play to the functions and effects of the annual report system of land reclamation, it is urgent to improve at the normative level. Therefore, under the framework of administrative supervision theory, based on the paradigm of legal interpretation, we can use the research method of normative analysis to conduct a comprehensive study on the review norms of land reclamation annual reports. The normative analysis involved, as a kind of research process and result, focus on the "legality of the law, the operational effect of the law, the substantive content of the law" [1]. By studying the meaning of legal norms on the surface and behind, "the analysis of the clarity and logic of legal rights and legal obligations," we then examine the constituent elements of law in an all-round way at the normative level ${ }^{[2]}$. This article mainly launches the demonstration and the judgment of the review norms of the land reclamation annual report and pays attention to the two kinds of matters of the review subjects and review methods of the annual report of land reclamation. Based on clarifying the normative meaning of each item, discover the problems existing in each item and improve it, aiming to improve the functions and effects of land reclamation annual report in land reclamation supervision.

\section{Analysis of the Review Subjects of Land Reclamation Annual Report Review Clauses}

The review subjects of land reclamation annual report review clauses are the administrative subjects responsible for receiving the annual reports of land reclamation and reviewing the authenticity of the contents. The analysis on the review subjects is to examine the "professionalism, specialization, independence, authority and efficiency" of its institutional settings and personnel allocation ${ }^{[3]}$.

a) The norms settings of review subjects of the land reclamation annual report

The existing norms of review subjects of the land reclamation annual report mainly stipulate the institutional settings and the personnel allocation. On the one hand, about the status of the review subjects, the relevant norms clarify that the review shall be 
implemented by the competent departments of natural resources (land and resources). For example, article 17 of the Regulation on Land Reclamation stipulates that the "land and resources competent departments of the local people's government at or above the county level" shall supervise the contents of the annual report of land reclamation. Article 22 of Measures for the Implementation of the Regulation on Land Reclamation stipulates that "county-level natural resources departments" shall supervise and verify the contents of the annual report of land reclamation. The Notice of the General Office of the Ministry of Land and Resources on the Compilation and Reporting of Protection of Mine Geological Environment and Land Reclamation Plans stipulates that mining enterprises shall report the land reclamation annual reports to "the competent departments of land and resources at or above the county level." Another example, article 32 of the Notice of the Ministry of Land and Resources on Printing and Distributing the Administrative Measures for the Reclamation and Utilization of Historical Abandoned Industrial and Mining Lands, stipulates that "the local land and resources departments at all levels" shall conduct the reviews. The Ministry of Land and Resources on the implementation of Land Reclamation Regulations Notice stipulates that "the relevant competent departments of land and resources" shall supervise the contents of the annual report of land reclamation. Article 14 of the Measures for the Implementation of the Regulations on Land Reclamation in Shaanxi Province stipulates that "the competent departments of land and resources of the people's government at the county level" check the contents. Another example, Jingdezhen Municipal People's Government Office on the Issuance of Strengthening and Improving Land Development and Consolidation Reclamation Supplementary Arable Land Work Notice stipulates that "the Municipal Bureau of Land and Resources shall work with the Municipal Finance Bureau and the Municipal Agriculture Bureau" to conduct regular and irregular spot checks. Article 21 of the Yongzhou Mining Geological Environmental Protection and Land Reclamation Measures stipulates that the "city, county and district administrative departments of land and resources" shall fulfill their responsibilities of supervision. Interim Measures for the Management of Cultivated Land Development and Reclamation Funds of Yunnan Province stipulates that land management departments and agricultural departments shall submit reports on the use of land reclamation funds to the "financial departments at the same level." On the other hand, about personnel allocation, the emphasis is placed on improving the qualities of review personnel and collaborations among personnel from different departments. For example, Opinions of the People's Government of Zunyi City on Strengthening the Work of Land Consolidation, Reclamation and Development stipulate that it is necessary to "strengthen team building and improve comprehensive quality." Article 7 of the Chongqing Municipal Land and Housing Administration on the Issuance of Chongqing Rural Construction Land Reclamation Project Management Regulations (Trial) Notice stipulates that the district and county land management departments shall review the reclamation projects in conjunction with the "agricultural and other departments and relevant professional and technical personnel."

\section{b) The problems of the review subjects of the land reclamation annual report}

We can see that the review subjects of the annual report of land reclamation are consistent with the supervision subjects of land reclamation, and the natural resources (land and resources) competent departments receive the annual statements and review the contents of the annual reports. On the one hand, the existing norms only endow the natural resources (land and resources) competent authorities the unified review power in terms of the setting of powers. Still, they do not further define the procedures of the exercise of power. And part of the collaborative functional departments is also mostly at the same level, whether the competent departments of natural resources (land and resources) can mobilize all kinds of regulatory resources to implement the substantive review of the land reclamation annual report is doubtful. After all, "land reclamation has the characteristics of comprehensiveness, technicality, systematization, regionality, diversity, etc., and is interdisciplinary with geology, soil science, land management science, environmental science, ecology, agronomy, sociology, engineering, mining, etc." ${ }^{[4]}$. It is hard to be completed by a single and independent department in charge of natural resources (land resources), and it is necessary to cooperate to a certain extent. On the other hand, the relevant norms have fewer requirements for the reviewers of the annual report of land reclamation. The existing provisions of personnel allocation mainly stipulate some specific and professional matters. They do not directly provide for the review of the normalized land reclamation annual report. For example, the demonstration of reclamation projects and the examination of land reclamation funds need relevant professional technicians. According to the current personnel structure, the composition of the reviewers of the annual report of land reclamation is too administrative, which leads to the decline of professionalism. To consider review efficiency, the personnel allocation of the review subject must take into account the quality and professional ability of reviewers.

c) The improvement paths of review subjects of the land reclamation annual report

On the one hand, we should promote the coordination of supervisory departments to supervise. 
For the institutional settings, "The regulatory departments conduct substantive reviews through cooperation" ${ }^{\text {[5] }}$. The basic pattern is that the government, natural resources department, environmental protection department, water management department, agriculture department, forestry department, transportation department, auditing department, and other departments should coordinate and cooperate within their professional terms of reference based on "community's mutual aid relationship attribute," and exercise their supervision and management powers in a centralized and unified way ${ }^{[6]}$. On this basis, it is necessary to strengthen the competent department of natural resources (land and resources) as the main body of supervision and management, to undertake the functions of convening, organizing, and so on. Considering that the annual report of land reclamation is reviewed once a year, in the future, it is necessary to establish an inter-departmental institute for deliberation and consultation or a temporary review group to conduct the reviews. The inter-departmental institute mainly uses normalized communication channels. The competent departments of natural resources (land and resources) in the pursuit of consistency of regulatory purposes, through extensive communication and functional cooperation to expand the efficiency of administrative supervision. The pattern of the review group for the annual report of land reclamation is that the competent department of natural resources (land and resources), based on the size, complexity, and time required of the annual report of land reclamation, leads the establishment of an organization called "social entities pursuing certain goals" and conducts a comprehensive review of the annual report of land reclamation in the form of responsibility ${ }^{[7]}$.

On the other hand, we should also improve the abilities of supervision and management of supervisors. First of all, with the continuous applications of various types of information technologies, land reclamation supervision also keeps using new technologies, which requires supervisors must have the dual abilities of onsite inspection and off-site surveillance. For this reason, administrative staff with traditional executive skills must accept regular personnel training. That is to say, in the process of land reclamation annual report supervision, it is necessary to pay attention to the study of technology, engineering, and other businesses, and gradually cultivate a coordinated supervision team of professionals with knowledge of water conservancy, soil, and environmental protection. Only in this way can it better meet the land reclamation annual report supervision under the new form. Secondly, the reviewers of the annual report of land reclamation should recruit experts, public lawyers, accountants, and so on with relevant professional knowledge to a certain extent. The reports not only undertake the functions of reviewing and providing references for decision-making, but also needs to face the disputes on property rights of the land, review of different types of funds, enterprise review, and so on. Therefore, we will have appropriate personnel to deal with technical issues, legal issues, and funding review issues that may arise during the review process. Finally, excessive pursuit of professionalism and impartiality of the review will reduce the efficiency of the investigation. We need to adjust the personnel allocation based on the contents of the reports. For general and low-complexity contents, they can be quickly handled by staff without a professional background. As for the information that are highly professional and complex, relevant personnel needs to take the accuracy of the review as the first standard and take it seriously.

\section{Analysis of the Review Methods of Land Reclamation Annual Report Review Clauses}

The review methods of land reclamation annual report review clauses refer to the methods and forms of reviewing the reports. The analysis on the review methods of the land reclamation annual report review clauses aims to examine the richness and rationality of the review methods to enhance the professionalization of the review subjects at the level of operation mode.

\section{a) The norms settings of review methods of the land reclamation annual report}

Existing land reclamation annual report norms in the review methods mainly provide two ways of off-site policing and on-site inspection. For off-site supervision, it includes remote sensing monitoring, supervision information platform monitoring, information management systems, etc. For example, article 11 of Rules for the Implementation of "Double Random and One Disclosure" Supervision and Inspection of Land Reclamation stipulate that the Ministry of Land and Resources shall conduct investigations through "remote sensing monitoring 'one map' and comprehensive supervision platform." The Notice of the Ministry of Land and Resources on Implementing the Regulation on Land Reclamation stipulates "technical means such as 'one map' throughout the country." Another example, article 11 of Notice of Guangdong Provincial Department of Land and Resources on the Implementation Rules of "Double Random and One Disclosure" Supervision and Inspection of Land Reclamation stipulates the supervision methods of "remote sensing monitoring 'one map' and comprehensive supervision platform." Notice from the Office of Ningde Municipal People's Government on Further Regulating the Work of Land Consolidation, Reclamation and Development stipulate "Monitoring and supervision system of rural land consolidation." Another example, the Notice of the Department of Land and Resources of Guangxi Zhuang 
Autonomous Region on Strengthening the Management of Land Reclamation, stipulates the establishment of an "information management system." Article 25 of Notice of the General Office of the People's Government of Baotou on Issuing the Interim Measures for the Administration of the Reclamation and Utilization of Abandoned Industrial Mining Lands and Abandoned Residential Areas in Baotou stipulates "comprehensive supervision platform of Land and Resources." For onsite inspection methods, they are mainly random spot inspections. For example, article 11 of the Implementation Rules for Supervision and Inspection of "double random and one Disclosure" of Land Reclamation stipulates "on-site random inspections." Article 24 of Yongzhou Mine Geological Environment Protection and Land Reclamation Measures stipulates the review method of "on-site inspection." Another example, article 11 of the Announcement of Guangdong Provincial Department of Land and Resources on the Implementation Rules for the Supervision and Inspection of "Double Random and One Disclosure" of Land Reclamation stipulates "on-site random inspections." The Notice of the Guangxi Zhuang Autonomous Region Land and Resources Department on Strengthening the Management of Land Reclamation stipulates an "inspection or spot check" system. Another example, the Notice of the Jingdezhen Municipal People's Government Office on Printing and Distributing Opinions on Strengthening and Improving Land Development, Arrangement, Reclamation, and Supplementary Farmland, stipulates a "spot check" system.

b) The problems of review methods of the land reclamation annual report

The review methods of the reports are composed of off-site supervision and on-site inspection, which are reasonable in composition. However, the application of review methods still needs to be further improved. On the one hand, the annual report of land reclamation pays more and more attention to the use of off-site supervision in the review methods, especially the use of remote sensing monitoring technology and information management system, and the use of this review method is connected with the information monitoring system. The content of the annual land reclamation report itself is also the source of information for land reclamation information monitoring. However, off-site supervision, as "a continuous and resourceintensive supervision," has the characteristics of vast coverage and strong continuity, which can continue to expand ${ }^{[8]}$. Based on the existing monitoring technology, it is necessary to introduce new monitoring technology, and we should also promote the integration of monitoring resources. And we need to strengthen the ability to process the contents of land reclamation annual reports through information technology. On the other hand, the function of on-site inspection is too mechanized. On-site inspection can not only make up for the lack of supervision of off-site supervision but also play a decisive role when the review results are in doubt. However, we should also see the disadvantages of high cost and low efficiency of on-site inspection. It is precise because of this that we should discuss the use of onsite inspections. We can't directly determine the proportion of random spot checks based on factors such as the number of review tasks and the ability of the review subject and then conduct random spot inspections on a large scale. On this basis, we should consider the combined use of on-site inspection and offsite supervision.

\section{c) The improvement paths of review methods of the land reclamation annual report}

On the one hand, we should refine off-site supervision methods. Off-site supervision is "a mode of remote inspection or verification carried out by supervisors who are not at the scene of the supervised objects" [9]. At present, modern information technology methods such as remote sensing, GIS, and sensors are the core in the review of the annual report of land reclamation, and they are relatively mature. We should use them on a large scale. It is also necessary to hold an open attitude towards the applying of new information technologies, including VR, artificial intelligence, big data, etc. In principle, the more information collected through off-site information collection methods, the better. Especially in the management and application of big data, data management, data interaction, data analysis, and so on have become the key to the review and early warning of future land reclamation annual reports. The supervision of the annual report of land reclamation belongs to the supervision of the whole process. It will face the problems such as "a large amount of data information, complex information attributes and topological relationships, and large changes in information time and space $^{\|[10]}$. To achieve this goal, supervisors need to build functionally differentiated management systems based on their needs, such as positioning systems, information collection systems, data processing systems, data management systems, etc. Each management system has different characteristics according to its functionality; for example, the data processing system must have the ability of big data processing and analysis and be able to provide scientific analysis reports to supervisors, decisionmakers, etc., in a short time. Simultaneously, considering that our country has built the management systems step by step according to the administrative level, the information interaction and information fusion between various administrative regions also need further to be integrated and improved.

On the other hand, we should emphasize the synergy between off-site supervision and on-site 
inspection. There is no question of which is better or worse between on-site examination and off-site surveillance. The two are complementary in function, and the basis for the synergy between the two is the linkage between the two. We can achieve it through the "off-site and on-site communication system" or information-sharing mechanism ${ }^{[11]}$. For the contents that are difficult to cover, doubtful, or important in off-site supervision, we can confirm them through an on-site inspection to give full play to the guiding role of off-site supervision on on-site inspection and enhance the pertinence and effectiveness of on-site inspection. In turn, the outcomes of the on-site examination can also correct the results of off-site surveillance and improve the accuracy of the review. It is necessary to "adjust measures to local conditions and time conditions" ${ }^{\text {I[12] }}$. Since both off-site supervision and on-site inspection are affected by the environment, it is necessary to select the appropriate review methods based on environmental changes. That is to say; the review subjects choose more cost-effective review methods based on various factors. The review subjects need to form a review planning scheme in the early stage of the review and then implement it. Also, we can expand the specific methods of on-site inspection. Under the condition that it is unnecessary to have on-site inspections by full-time reviewers, the reviewers shall be allowed to entrust qualified institutions, qualified personnel, or general grassroots organizations to conduct on-site inspections.

\section{ili. Conclusion}

The normative analysis of China's land reclamation annual report review clauses is related to the proposition of the "responsive law" of the administrative supervision ability. Under the guidance of the paradigm of legal interpretation, this article uses the research method of normative analysis to explore the specific operation problems of reviewing the land reclamation annual report in functions and effects. First of all, classify and characterize the relevant norms of the annual report review of land reclamation. Furthermore, through the analysis of the review subjects and review methods, the problems existing in the review of land reclamation annual report are found, and specific improvement paths are proposed. For the problems of poor coordination and incomplete personnel composition of the review subjects, it is necessary to improve the coordination of supervision departments and the supervision ability of supervision personnel. For the unreasonable applications of land reclamation annual report review methods, we should solve the issues by deepening the off-site supervision methods, emphasizing the synergy of off-site supervision and onsite inspection.

\section{References Références Referencias}

1. Xie Hui, On Normative Analysis Method, 2 Chinese Law (2009).

2. Tan Xiao, The Method Composition and Application Scope of Normative Law, 4 Science of Law (Journal of Northwest University of Politics and Law) (2012).

3. Yang Yehong, Research on the Subject of Reviewing the Legitimacy of Major Administrative Decisions, 4 Journal of Hunan University of Science and Technology (Social Science Edition) (2017).

4. Zhou Yan, Bai Zhongke, Luo Ming, Zhou Xu, Wang Jinman, Jing Ming, Problems and Countermeasures of China's Land Reclamation Supervision System, 2 China Land Science (2014).

5. Zhao Qian, Agency Framework and Governance: Normative Analysis on Organization Provisions of Land Reclamation Regulation, 5 Oriental Law (2018).

6. Zhao Qian, Mutual Aid and Self-sufficiency: The Community Relationship and Function of Land Reclamation Regulatory, 8 Journal of Jinan (Philosophy and Social Science Edition) (2017).

7. SUN ZEHOU \& LUO FAN, MANAGENENT PSYCHOLOGY AND BEHAVIOR, at 400 (Wuhan University of Technology Press, 2003).

8. Wang Zhaoxing, Off-site Supervision: Function, Positioning and Effectiveness, 5 Financial Supervision Research (2012).

9. Hu Wei, The Off-site Supervision in the Era of Big Data, 17 China Finance (2015).

10. Wang Yuan, Kang Yanli, Chen Yingyi, Current Situation and Countermeasures of Supervision and Management of Land Reclamation in Abandoned Mines, 13 Environmental Protection (2010).

11. Wu Zuhong, Policy Recommendations for Improving the Off-site Supervision System, 3 Financial Theory and Practice (2004).

12. Zhou Wei, Cao Yingui, Bai Zhongke, Wang Jinman, Discussion on Monitoring Index of Land Reclamation in Coal Mining Area, 11 China Land Science (2012). 